\title{
Article \\ A Modular Wave Energy Converter for Observational and Navigational Buoys
}

Nicholas Vella, Jamie Foley, James Sloat, Alexander Sandoval, Leonardo D'Attile and Masoud Masoumi *

check for

updates

Citation: Vella, N.; Foley, J.; Sloat, J.;

Sandoval, A.; D'Attile, L.; Masoumi,

M. A Modular Wave Energy

Converter for Observational and

Navigational Buoys. Fluids 2022, 7,

88. https://doi.org/10.3390/

fluids7020088

Academic Editors: Ioannis K.

Chatjigeorgiou and Dimitrios N.

Konispoliatis

Received: 10 January 2022

Accepted: 18 February 2022

Published: 21 February 2022

Publisher's Note: MDPI stays neutral with regard to jurisdictional claims in published maps and institutional affiliations.

Copyright: (C) 2022 by the authors. Licensee MDPI, Basel, Switzerland. This article is an open access article distributed under the terms and conditions of the Creative Commons Attribution (CC BY) license (https:// creativecommons.org/licenses/by/ $4.0 /)$.
Department of Mechanical Engineering, Manhattan College, Riverdale, NY 10471, USA; nvella01@manhattan.edu (N.V.); jfoley01@manhattan.edu (J.F.); jsloat01@manhattan.edu (J.S.); asandoval01@manhattan.edu (A.S.); ldattile01@manhattan.edu (L.D.)

* Correspondence: mmasoumi01@manhattan.edu

\begin{abstract}
More than $80 \%$ of the ocean is not fully mapped or even observed, even though it covers over $70 \%$ of our planet's surface. One of the primary challenges for ocean observation and monitoring is the required power for exploration and monitoring systems, which often operate in remote areas of the ocean. This work addresses the design and development of an ocean wave energy converter that can be installed on observational buoys to provide enough power for sensors, cameras, data acquisition and recording, as well as data transfer units. The initial simulations of the prototype indicate that this system can produce up to 3.7-3.85 watts of power on average, with greater than 12 watts of maximum power in two selected sites in California and Hawaii. The proposed system is simple and low-cost. Further, multiple energy converters can be installed on one buoy to address higher power needs.
\end{abstract}

Keywords: wave energy; energy harvesting; ocean observation; instrumented buoy

\section{Introduction}

Ocean observation and continuous coastal monitoring have various important applications, from marine navigation and operation, monitoring coastal hazards, military operations to coast guard's search, and rescue missions and scientific research. Ocean and weather forecasting can potentially influence our sources of food, jobs, security, and energy resources. Therefore, it is essential to continuously observe ocean characteristics, properties, and its ecosystem [1-3].

The advancement of measurement technologies, sensors, and recording devices have had a great impact on ocean observation and monitoring. New sensors are more compact, sensitive, reliable, compact, and lightweight, and they consume less energy to record and transfer the data. These changes, along with the rapidly increasing need for sustainable development, accelerated the effort to develop more efficient measurement systems for mapping the ocean, and also real-time and long-term monitoring of coastal regions. The complete and accurate measurements that can be used for understanding the ocean's dynamics and monitoring its state are typically taken using both satellite imaging and in situ recordings [4]. Among the various challenges involved in in situ measurements is the energy needed to power sensors and data acquisition systems. The power requirement is one of the primary limiting factors in developing systems that can provide measurements over large areas with small spatial resolution.

The power required to run a wave logger is as low as 10 milliwatts, while a pressure or temperature sensor can use up to 700-800 milliwatts of power. This power requirement can increase up to watt-level for mobile ocean monitoring platforms, such as low-cost sensor buoy systems, current profilers, buoys with automatic monitoring systems, and autonomous underwater vehicles [5]. According to a study published by the National Renewable Energy Laboratory and based on the responses gathered from 68 experts, 
41 SurveyMonkey respondents and 27 telephone or in-person interviews, power limitation has been mentioned as one of the main concerns in ocean observation [6].

One of the possible solutions to address the power requirements of buoys is to use solar energy. A photovoltaic (PV) power-generation system can be implemented on a buoy to reduce the dependency on batteries. Dating back to 1970, initial implementation of solar panels to charge nickel cadmium and lead acid batteries on buoys over a period of 6 months revealed no deterioration in performance, even during extreme weather conditions [7]. Since that time, there have been numerous studies to investigate the effectiveness and possible optimization of solar panels usage to power buoys and other ocean monitoring systems [8-11]. The low cost, simplicity, and high reliability deems solar energy the first possible option for power generation when the monitoring system is present at the ocean's surface [12]. There has also been published work focusing on the required modules for power management and monitoring of solar-powered buoys. As an example, an energy monitoring system for a solar-powered ocean buoy was developed and tested by Hegarty et al., where the monitoring system with dimensions of $300 \times 230 \times 87 \mathrm{~mm}$ was attached to a Mobilis DB 8000 Acoustic buoy equipped with solar panels [13]. This system was specifically designed to quantify the energy production from the PV panels as well as for fault detection purposes.

Although PV power-generation systems, including buoys for observation and monitoring, have been implemented on marine structures, there are some drawbacks concerning these energy-generation systems in the ocean environment. These systems require frequent maintenance and cleaning to prevent power conversion efficiency loss due to bird drippings, corrosion, and biofouling. Further, PV panels are limited by the available surface on the buoy. They are also ineffective and impractical at higher latitudes. As an alternative, there has been great effort to develop and integrate ocean wave energy harvesting systems into buoys. The ocean is a great source of energy, and harnessing that energy can greatly help increase the lifespan of buoys and also limit the required maintenance.

Harnessing ocean wave energy to power instrumented buoys has always been considered a possible solution to the power limitation problem for in situ ocean observation [14,15]. However, the increase in power demand due to the growth of more advanced sensors, recording devices, as well as communication and data processing units implemented on oceanographic and meteorological buoys has highlighted ocean waves as another potential source of available energy. The development of energy harvesting systems for instrumented buoys is largely focused on generating power using simple designs that can produce sufficient power from the heaving motions of a buoy, differing from the efforts to develop large-scale wave energy conversion systems [16]. As a result, there have been small-scale energy harvesting devices introduced to power instrumented buoys.

Davis et al. proposed a conceptual design for a floating wave energy system as a simple, low-cost, buoy-size platform for ocean observation [17]. The design could theoretically produce up to 50 watts of power. A proof-of-concept system was built and tested to investigate the feasibility of the design, which could successfully generate more than 50 watts [18]. A hybrid PV-ocean wave-powered buoy was later designed and tested by Gemme et al. [19]. The system includes a linear generator and PV panels. The initial laboratory testing showed that the proposed design could generate up to 10.2 watts of average power with peaks greater than 70 watts. This hybrid system was a continuation of an initial design, which only included a linear generator for wave energy harvesting [20]. Following this development, Herne et al. introduced a "chain"-like platform, which consisted of multiple spring-mass magnet units [21]. This system can generate 2 to 100 milliwatts $/ \mathrm{kg}$ in $0.1-0.7 \mathrm{~Hz}$ frequency range. The mass of the system depends on the number of cells used to construct the chain. Further, Wu et al. introduced a two-way energy-absorption turbine installed on a floating device for profiling purposes [22]. This system was capable of generating power in both shallow and deep water due to its blade-wave interaction design.

The energy harvesting system proposed in this work is an ocean wave power generation unit that can be implemented on both currently operational and newly designed 
buoys. The special configuration of the magnets and the use of separate coils in this design provides a robust, compact, and high density power generation system. The aim of this design was to develop a simple system capable of producing enough power for sensors and data transfer units in a low-cost instrumented buoy. Further, the design of this energy harvester can be adapted for installation on various types of buoys and to address a range of power requirements. In order to increase power generation, multiple energy harvesters may be installed on each buoy.

\section{Materials and Methods}

\subsection{Overview of the System}

The proposed energy harvester consists of a set of magnets, specially configured to provide a strong and compact magnetic field, metal pole pieces to maintain the distance between the magnets, a set of springs for levitation and frequency up-converting, and two end-magnets to form a braking system under extreme wave conditions. In the proposed magnetic arrangement, each magnet's north pole is facing its neighboring magnet's north pole, constituting a set of magnets assembled with strong repulsive forces between them. These magnets are kept in place using a threaded rod, passed through the magnets and pole pieces. Figure 1 provides a general view of the designed prototype. The upper collar is a disk-like foam added to keep the prototype afloat during testing. Further, there are four separate coils in the prototype, which are all represented as one coil in the figure for simplicity.

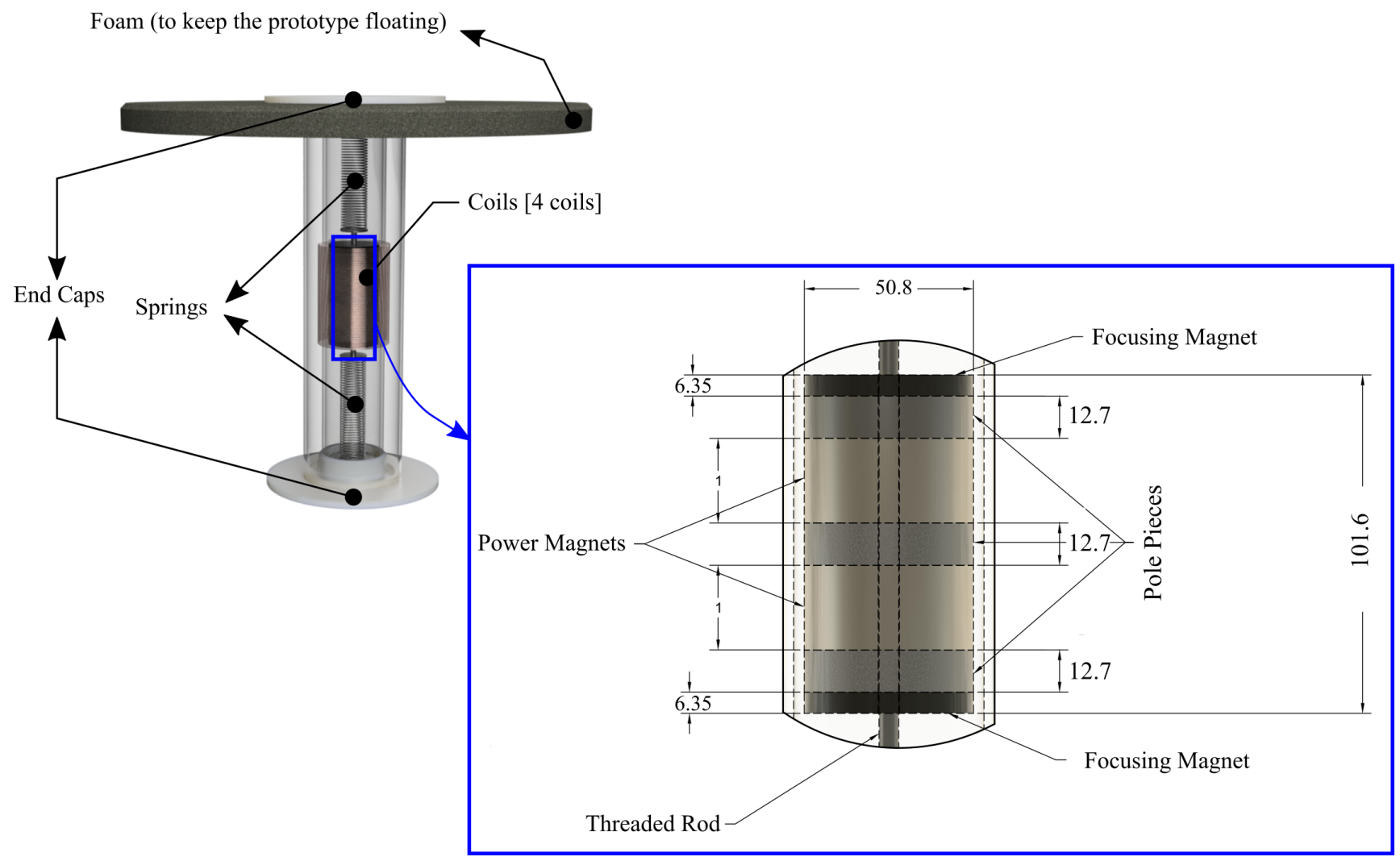

Figure 1. General view of the prototype and the structure of the rotor (all dimensions are in millimeters).

Figure 1 also provides a drawing of the rotor with two power magnets, three pole pieces, and two focusing magnets. The focusing magnets are thinner than power magnets, as they were not intended to produce magnetic fields for power generation purposes. Table 1 lists the materials used for building this prototype. 
Table 1. Materials list for the prototype. Other items were also used as part of the fabrication and assembly process, including clear PVC cement, washers, and electric components, such as wires, electrical resistors, capacitors, and electric tape. (OD: Outer Diameter, ID: Inner Diameter, Th.: Thickness).

\begin{tabular}{ll}
\hline Component & Description (All Dimensions Are in Millimeters) \\
\hline Power Magnet & $50.8 \mathrm{OD}, 6.35 \mathrm{ID}$, and 25.4 Th. \\
Braking Magnet & $50.8 \mathrm{OD}, 6.35 \mathrm{ID}$, and 6.35 Th. \\
Focusing Magnet & $50.8 \mathrm{OD}, 6.35 \mathrm{ID}$, and 6.35 Th. \\
316 Stainless Steel Rod & $50.8 \mathrm{OD}$ \\
Lexan Cylinder & $101.6 \mathrm{OD}$ and 95.25 ID \\
Lexan Cylinder & 57.15 OD and 53.975 ID \\
PVC End Cap & 76.2 OD \\
Springs and Spring Anchors & Various Stiffness (for testing) \\
Stainless Steel Threaded Rod & 6.35 Diameter \\
Coil & 95.25 OD and 57.15 ID \\
Silicone Sealant & Marine Grade \\
\hline
\end{tabular}

\subsection{Modeling}

In its operating environment, the energy harvester generates electricity due to the oscillation of the rotor with respect to the coils. The force applied to the top and bottom braking magnets during this oscillation can be found in the Ref. $[23,24]$

$$
F_{\text {top }}(x)=\sum_{n=0}^{3} a_{n}\left(d_{o}-x\right)^{n} \quad \text { and } \quad F_{b o t}(x)=\sum_{n=0}^{3} a_{n}\left(d_{o}+x\right)^{n}
$$

where $d_{0}$ is the distance between the rotor and the end magnets, $x$ is the relative displacement of the rotor, and subscripts top and bot indicate the values for the top and bottom braking magnets, respectively. The restoring force can then be calculated using [24]

$$
F_{\text {res }}(x)=F_{b o t}(x)-F_{t o p}(x)=k x+\alpha x^{3}
$$

where $k$ and $\alpha$ are the coefficients of the nonlinear spring which can be used to model the nonlinear levitating motion of the rotor.

The motion of the rotor can be considered a base excitation of a single degree-offreedom nonlinear spring-mass-damper system. This motion is modeled using [23]

$$
m \ddot{z}+c \dot{z}+k z+\alpha z^{3}=F(t)
$$

where $k$ and $\alpha$ are the constants for the nonlinear spring, $m$ is the mass of the rotor, $c$ is the damping in the system, and $F(t)$ is the input force. The damping coefficient here includes both electrical and mechanical damping and the force is applied to the system by the ocean waves. Since this harvester is designed to be installed on a buoy for power generation, this force is the force transferred to the harvester due to the wave-buoy interaction.

The force applied to the system can be taken into account using the Morison force (per unit length) exerted on a cylindrical object [25]

$$
M_{F}=\frac{\pi}{4} C_{M} \rho D^{2} \dot{u}-\frac{\pi}{4} C_{A} \rho D^{2} \ddot{x}+\frac{1}{2} C_{D} \rho D|u \pm U-\dot{x}|(u \pm U-\dot{x})
$$

where $C_{M}$ is the inertia coefficient, $\rho$ is the water density, $D$ indicates the body diameter, $C_{A}$ is the added mass coefficient, $C_{D}$ is the drag coefficient, $u$ and $\dot{u}$ are the water particle velocity and acceleration due to the wave along the x-axis (parallel to the ocean's surface), $\dot{x}$ and $\ddot{x}$ are the velocity and the acceleration of the cylindrical body, and $U$ is the current velocity along the x-axis. Further, $C_{M}=1+C_{A}$ [25]. 
The buoy is secured such that it does not displace from its target location, but can still move about its axes with wave motion. The modeled buoy is tethered to the seabed by a chain link catenary mooring system. The mooring system is modeled by considering the horizontal tension, the submerged weight of the catenary connection, the angle of the catenary connection, the vertical depth, and the length of the catenary between the object and the seabed. See the Ref. [26] for more details.

The various components and sub-components of the proposed design were studied using three principal tools. The magnetic field modeling and simulations were conducted using Finite Element Method Magnetics (FEMM) software [27], the wave-buoy interaction and the electro-mechanical components of the system were simulated in an OpenModelica environment [28], using the OceanEngineering library [26]. Further calculations and analysis were performed in a Python environment [29]. The flowchart shown in Figure 2 represents a general overview of these three main tools and how they were utilized together for system modeling and simulations.

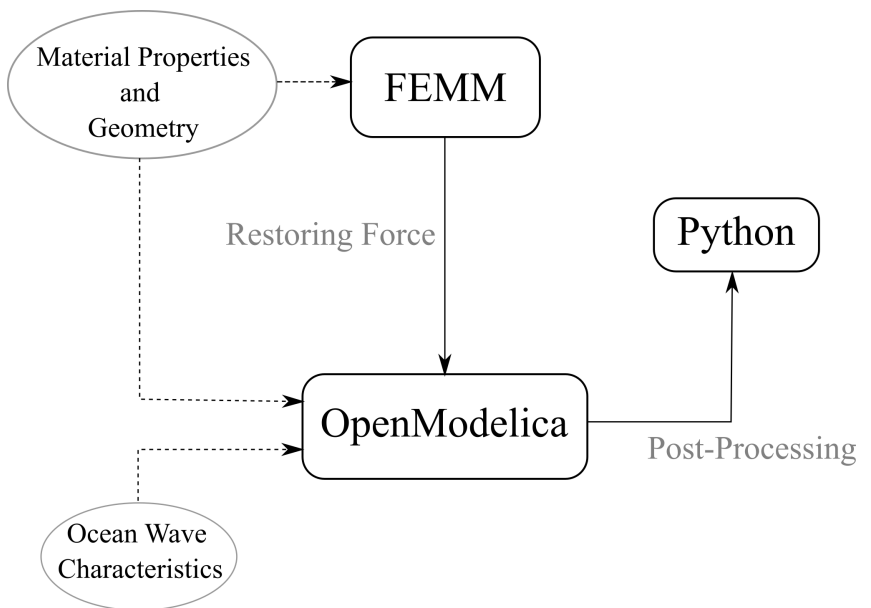

Figure 2. The flowchart represents the interaction between different tools used for system modeling.

\subsection{Experiments}

Wave tank testing was performed at the University of Rhode Island-Bay Campus, Narragansett, Rhode Island. The wave tank is $100 \mathrm{ft}$ by $12 \mathrm{ft}$ and has a depth of $4 \mathrm{ft}$. The wave generator is a paddle, hinged at the bottom to create required wave profiles. The setup is capable of generating both regular and irregular waves. The wave generator is controlled using a program written in the LabView [30] environment. Measurements were recorded using a capacitance WG-50 wave gauge built by Brancker Research Ltd, located near the device in the tank. The waves were generated using a bottom-hinged paddle wavemaker at one end of the tank. This wavemaker is actuated by a computer-controlled hydraulic jack. Further, the waves were partly absorbed by a parabolic shaped beach with a gradual slope out of the water to simulate a beach profile.

The wave-making paddle can generate waves with heights ranging from $2 \mathrm{~cm}$ to $10 \mathrm{~cm}$ and periods ranging from $0.5 \mathrm{~s}$ to $2 \mathrm{~s}$. Figure 3 demonstrates a schematic of the prototype placed in the wave tank during testing. The voltage output values were measured using a digital voltmeter. The minimum, maximum, peak-to-peak, average, and RMS voltage values for each four-minute run were recorded. The RMS values were then used to estimate the output power for each test. 


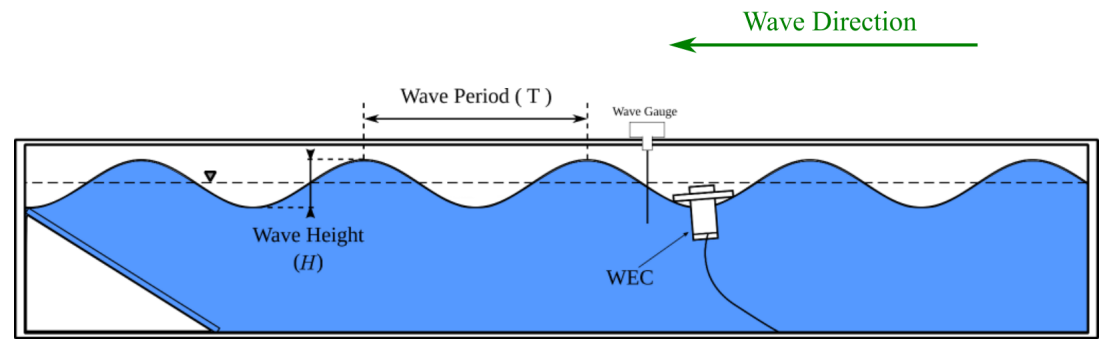

Figure 3. Schematic of the wave energy harvester in the wave tank, moored at the bottom (not drawn to scale).

\section{Results}

\subsection{Numerical Results}

\subsubsection{Magnetic Fields and Restoring Forces}

The structure of the rotor along with the braking magnets are modeled to determine the magnetic field distribution. Figure 4a shows the model in FEMM environment and Figure $4 \mathrm{c}$ represents the resulting magnetic field distribution. The model is axis-symmetric around the center line to provide a representation of the rotor structure. Further, the boundary around the structure was created in FEMM such that it emulates the impedance of an unbounded domain. The structure and the surrounding air was discretized to 23,700 elements with 12,132 nodes. As expected, the magnetic field is the strongest at the magnetic poles. Further, the pole pieces provide a "path" for the field and protect each magnet from magnetic field penetration by neighboring magnets.

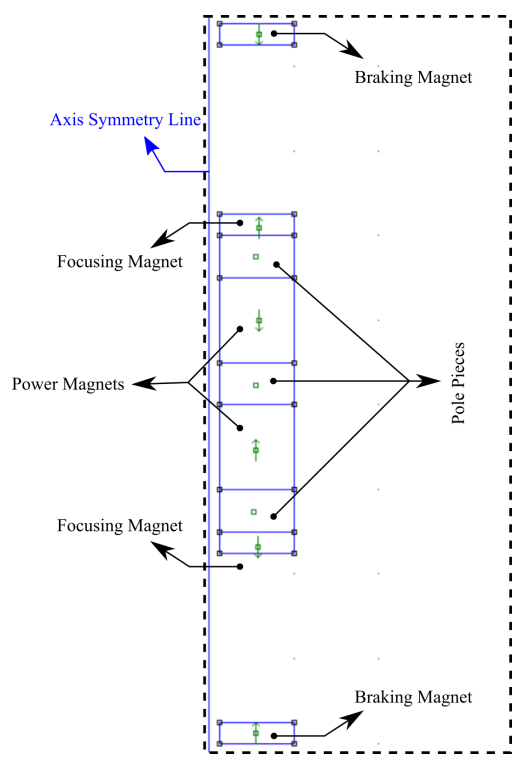

(a)

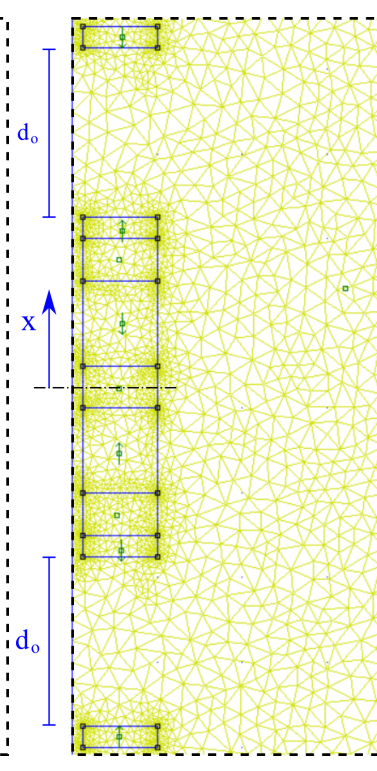

(b)
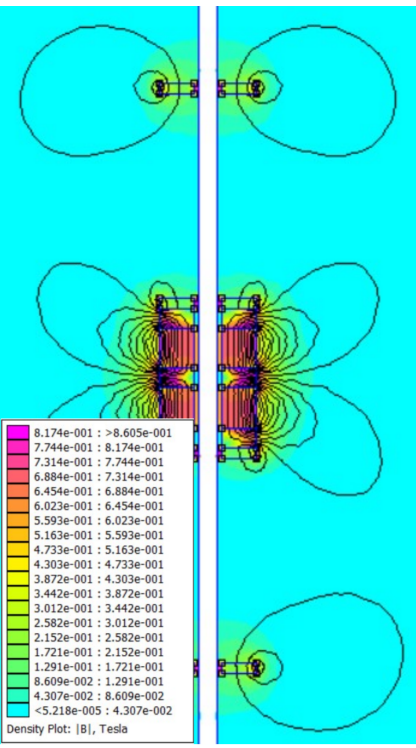

(c)

Figure 4. (a) Structure of the rotor and the braking magnet modeled in FEMM, (b) generated mesh in FEMM for finite element analysis, and (c) magnetic field distribution for the system.

In order to simulate the dynamic motion of the rotor and build a dynamic model of the system, the force applied to the rotor due to the braking magnets was calculated during the rotor's motion. This was performed by statically moving the rotor from the distance closest to farthest from the end magnet. The force exerted on the braking magnets was measured at each step. The restoring force produced by the top magnet can be measured as a function of the rotor's motion (by fitting a curve to the force magnitudes calculated using FEMM modeling), expressed as $F(s)=-33746.66 s^{3}+9076.19 s^{2}-0.775 .3 s+20.46$. Following the aforementioned steps in Section 2.2 and replacing the parameter $s$ with $\left(d_{0}-x\right)$ for the top 
magnet and $d_{0}+x$ for the bottom magnet, the values for the equivalent spring coefficients were calculated as $k=256 \mathrm{~N} / \mathrm{m}$ and $\alpha=67,493 \mathrm{~N} / \mathrm{m}^{3}$ for our system.

\subsubsection{Dynamic Modeling and Power Generation}

The energy harvesting system is designed to be part of an observational or navigational buoy. In order to assess the performance of this harvester as part of a buoy structure, we model the complete system, including the buoy, the energy harvester as a nonlinear spring-mass-damper system under base excitation, and the electrical circuitry. The Modelica programming language [31] (via OpenModelica interface) was employed due to its flexibility in modeling complex dynamical systems [28]. Figure 5 shows the general overview of the model developed in the software.

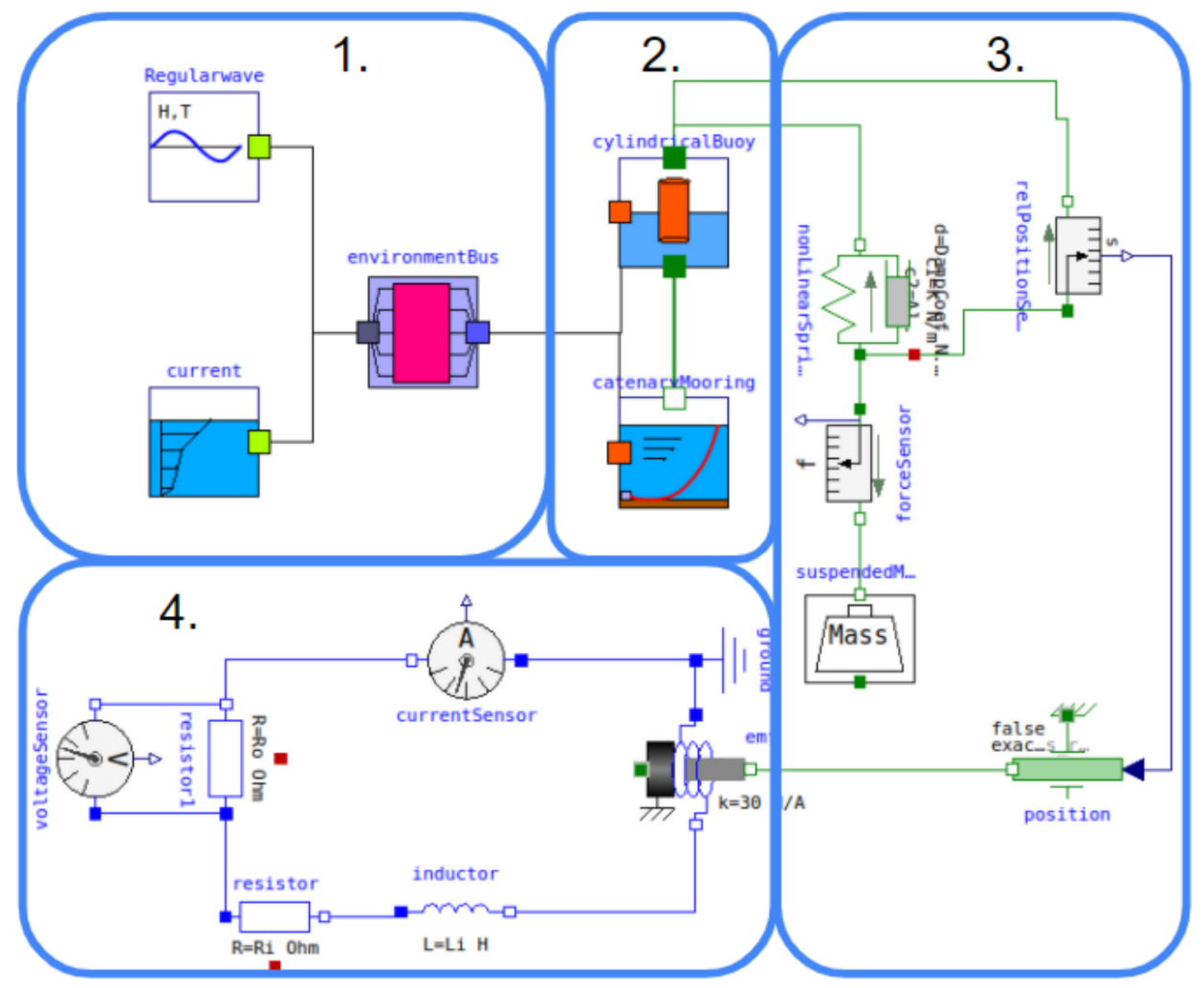

Figure 5. Complete model of the system in OpenModelica. The model includes the (1) environment, (2) buoy and mooring, (3) mechanical components, and (4) electrical components.

The subsystem 1 is the environmental input to the system, which includes ocean wave characteristics, such as irregular or regular wave categorization, the average time period and wave height values, the ocean's depth, and its current velocity. Subsystem 2 represents the buoy structure, mooring properties, and the calculated force exerted on the buoy, as described in Section 2.2. Subsystem 3 includes the single degree-of-freedom system composed of the nonlinear spring excited by the force applied to the buoy. Finally, subsystem 4 consists of the minimum electrical system required to convert mechanical motion into electricity.

To assess the performance of the prototype using the model, two sites in the U.S. coastal regions were selected: San Francisco, CA and Kapaau, HI. The wave characteristics for these two regions are listed in Table 2. The characteristics for the given locations were found using the NREL MHK Atlas database [32]. 
Table 2. Wave and current characteristics for the two selected sites (WD: Water Depth, WP: Wave Period, WH: Wave Height, EF: Energy Flux).

\begin{tabular}{cccccc}
\hline Location & WD $(\mathbf{m})$ & WP $(\mathbf{s})$ & WH $(\mathbf{m})$ & CS (m/s) & EF (kW/m) \\
\hline San Francisco, CA & 51.8 & 10.3 & 1.64 & 0.1574 & 14.11 \\
Kapaau, HI & 60 & 7.97 & 1.34 & 0.1513 & 8.13 \\
\hline
\end{tabular}

The model was developed for the prototype, which is a 1:2 scale model. Therefore, the wave height, wave period, and current velocity values were scaled so they could be used as the inputs to the environment subsystem in the model. The wave heights and wave periods were scaled using the Froude scaling laws [33]

$$
T_{m}=\frac{T_{f s}}{\sqrt{S}} \quad \text { and } \quad H_{m}=\frac{H_{f s}}{S} .
$$

Here, the subscript $m$ represents the parameters for the scaled model, $f s$ is the subscript for the full-scale prototype, $T$ is the time period, $H$ is the wave height, and $S$ is the scaling factor, which is 2 in this case.

The parameters used for the simulations are listed in Table 3. In this table, $R_{i}$ and $R_{o}$ are internal and external resistance values. The value of internal resistance was calculated based on the number of turns of each coil (1600 turns of 26 AWG wire) and the length of the winding. The stiffness for the top spring $\left(k_{t}\right)$ was larger than that of the bottom spring $\left(k_{b}\right)$ to keep the rotor with magnets and pole pieces closer to the middle of the external tube. Further, the inductance of the coil, $L_{i}$, was estimated using Wheeler's formula for inductance [34]. Finally, the damping constant, $c$, includes both mechanical and electrical damping and is an estimation for these simulations.

Table 3. Parameters used for the simulation in OpenModelica.

\begin{tabular}{ccccccc}
\hline Parameter & $R_{o}(\Omega)$ & $R_{i}(\Omega)$ & $k_{t}(N / m)$ & $k_{b}(N / m)$ & $L_{i}(H)$ & $c(N \cdot s / m)$ \\
\hline Value & 50 & 50 & 0.2 & 0.05 & 0.165 & 0.01 \\
\hline
\end{tabular}

For these simulations, we considered the wave energy converter to be a component of the SCOOP 2.1 buoy developed by NOAA. The dimensions and parameters for this buoy can be found in the Ref. [35]. Once the simulations were conducted, the power generated was scaled up to estimate the power for the full-scale prototype. Following the scaling law, the power was scaled using

$$
P_{f s}=S^{3.5} P_{m}
$$

where $P$ is the power generated. The results are shown in Figures 6 and 7 for both locations.

Based on the simulation results for the San Francisco location, the full-scale maximum power reached was 12.25 watts. The Root Mean Square (RMS) value of power in the model was 0.34 watts and 3.85 watts in the full-scale system. According to the results for the Kapaau location, the full-scale prototype's maximum power was 12.2 watts. The RMS value of the power output was 0.32 watts for the scaled model and 3.72 watts for the full-scale system. All these simulations were performed for $4 \mathrm{~min}$ intervals. 

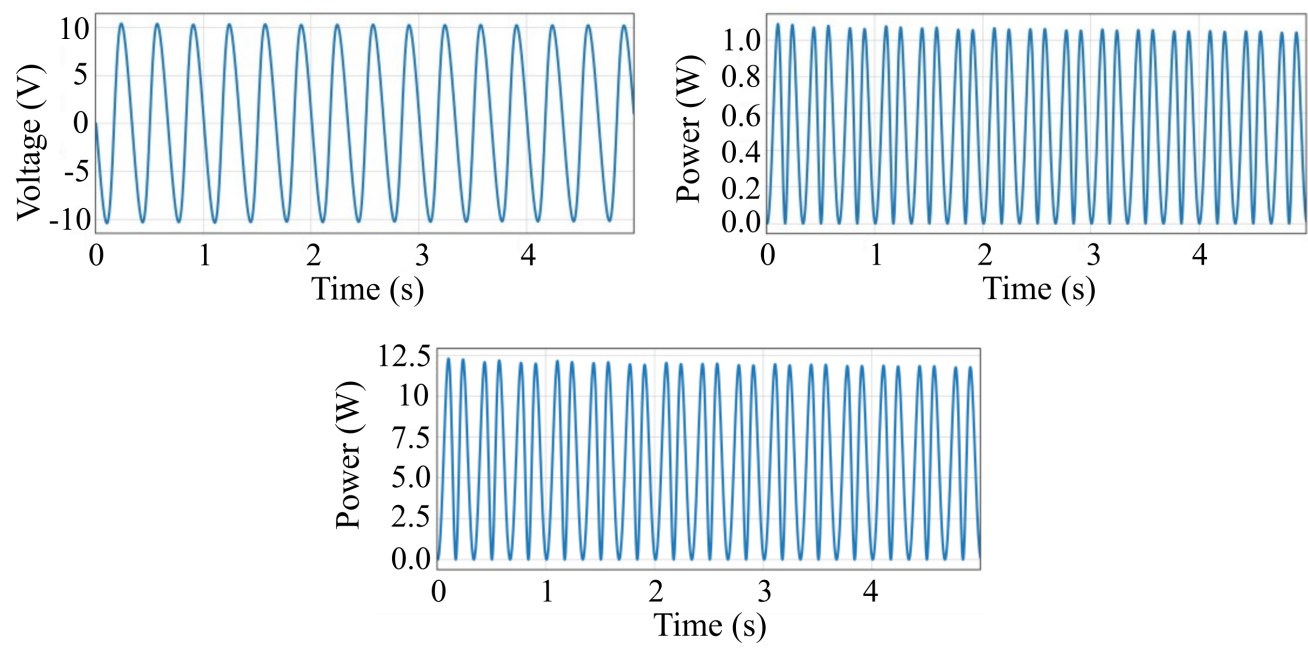

Figure 6. The output voltage for the model (top left), the output power for the model (top right), and the output power for the full-scale system (bottom). Results are for the San Francisco location.
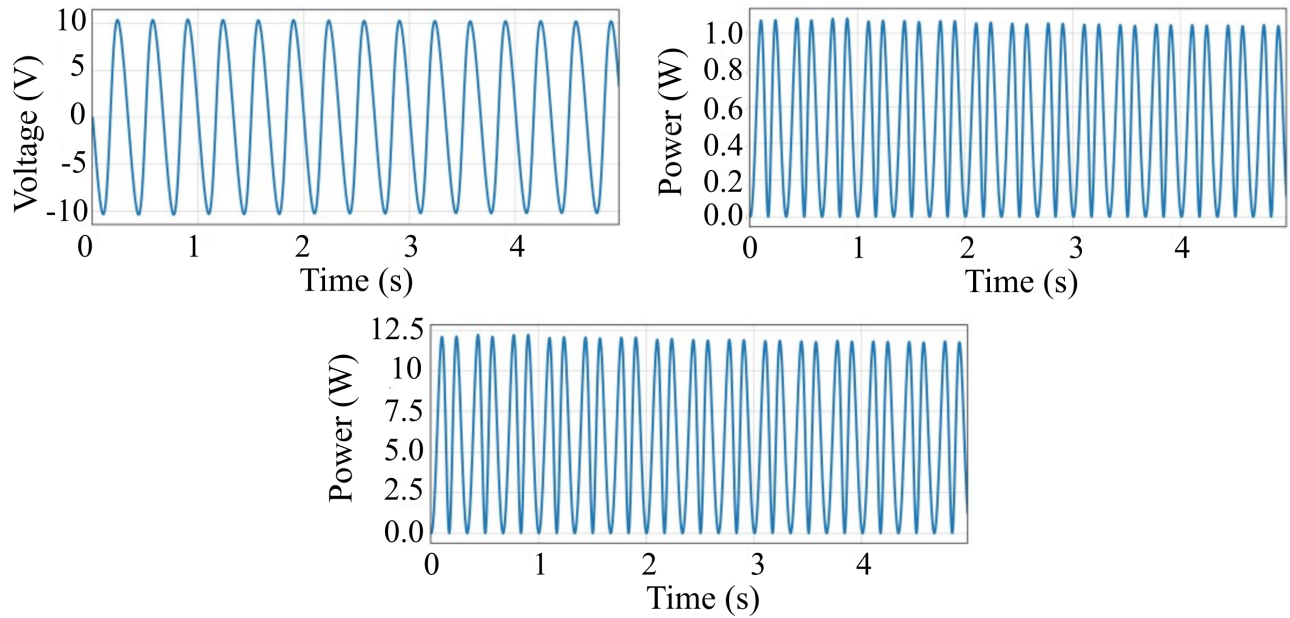

Figure 7. The output voltage for the model (top left), the output power for the model (top right), and the output power for the full-scale system (bottom). Results are for the Kapaau location.

\subsection{Experimental Results}

The prototype was built and assembled using the parts and components mentioned in Section 2. However, there were some modifications in the design. First, only one spring was used to keep the rotor within the tube levitated. Second, we only used one braking magnet at the top of the harvester. This change was due to the small waves that the prototype encountered in wave tank testing. These smaller waves did not create enough motion to cause the oscillating rotor to reach the end of its stroke. We also built a conventional four-phase full wave bridge rectifier with filtering capacitors. This circuitry was protected from the water's waves using a simple tube-like collar at the top of the device. Figure 8 shows the prototype with sub-components. In this prototype, the end caps were 3D-printed and attached to the ends of the tube using clear silicone sealant. 


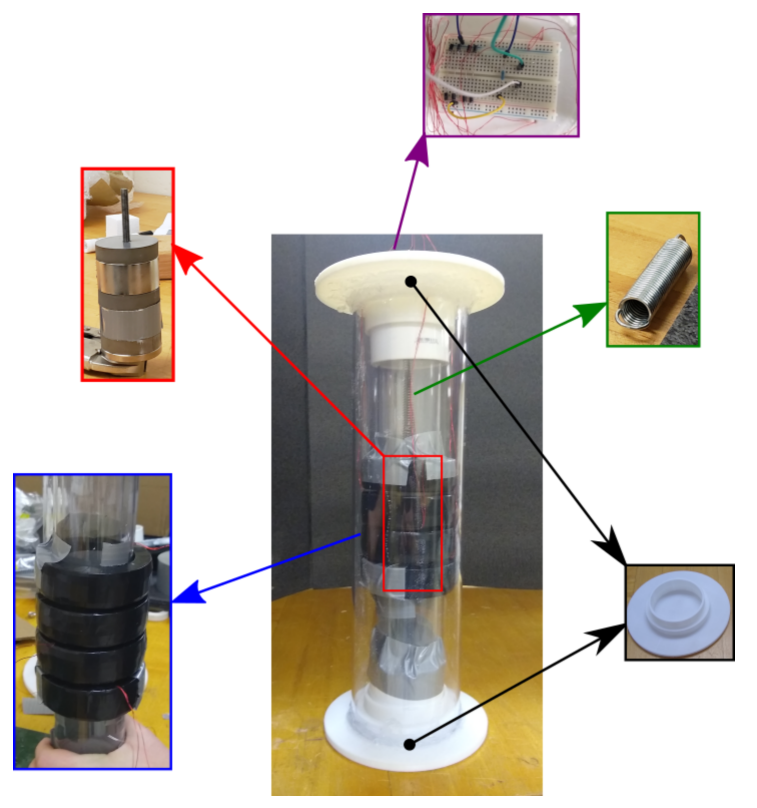

Figure 8. The prototype with some of its sub-components.

The device was tested under both regular and irregular waves. Figure 9 shows the harvester in the wave tank during experimental measurements.

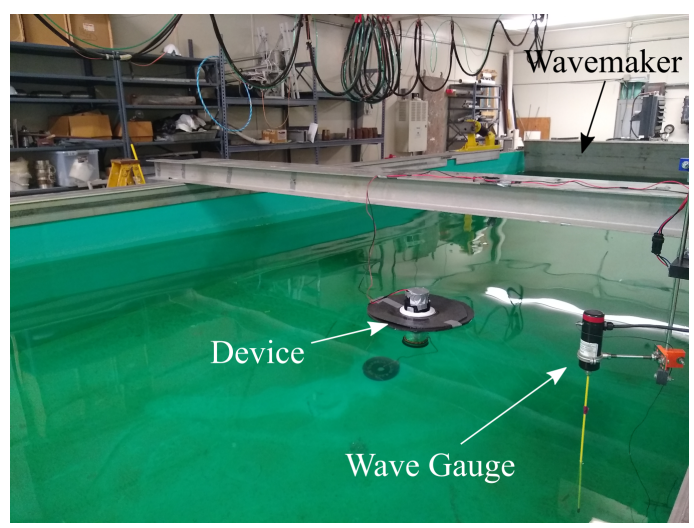

Figure 9. Experimental setup showing the wave energy converter in the wave tank.

Tables 4 and 5 display the wave characteristics used for testing of regular and irregular waves, respectively. The initial tests were conducted for regular waves with the characteristics listed in Table 4 . The irregular wave characteristics were determined based on the power output calculated for regular wave experiments. Figure 10 provides two samples of water elevation measured by the wave gauge during the experiments.

Table 4. Wave characteristics used for regular wave testing.

\begin{tabular}{ccccccc}
\hline Wave Period $(\mathrm{s})$ & 0.5 & 0.75 & 1 & 1 & 1.25 & 1.5 \\
\hline Wave Height $(\mathrm{cm})$ & 3 & 5 & 7 & 10 & 10 & 10 \\
\hline
\end{tabular}

Table 5. Wave characteristics used for irregular wave testing.

\begin{tabular}{ccc}
\hline Peak Spectral Period $(\mathrm{s})$ & 0.75 & 1 \\
\hline Significant Wave Height $(\mathrm{cm})$ & 10 & 10 \\
\hline
\end{tabular}



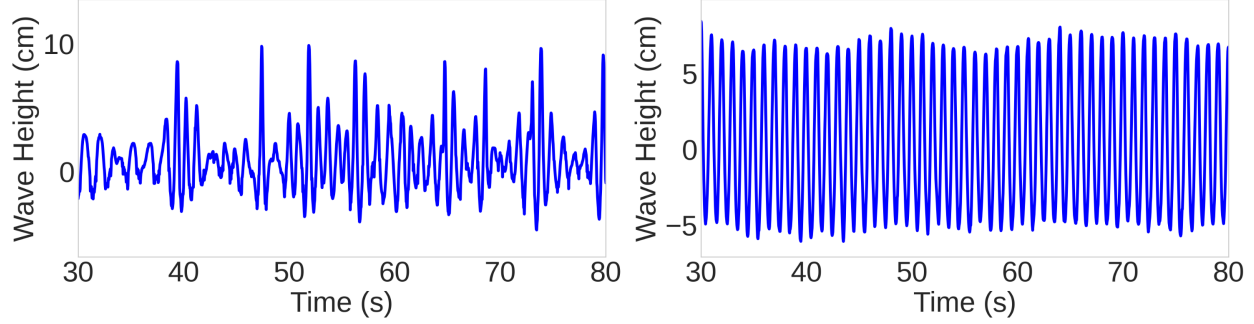

Figure 10. Samples of water elevation measured by the wave gauge during regular wave testing (right) and irregular wave testing (left).

Since the prototype is 1:2 scale, the power output measured was scaled to an estimate of the power generated by the full-scale system given these wave conditions. The power output calculated for both the scaled prototype and the full-scale system undergoing the wave conditions, listed in Tables 4 and 5, are shown in Figure 11. The power output values was calculated using the RMS value of the measured voltage and the resistance in the system.

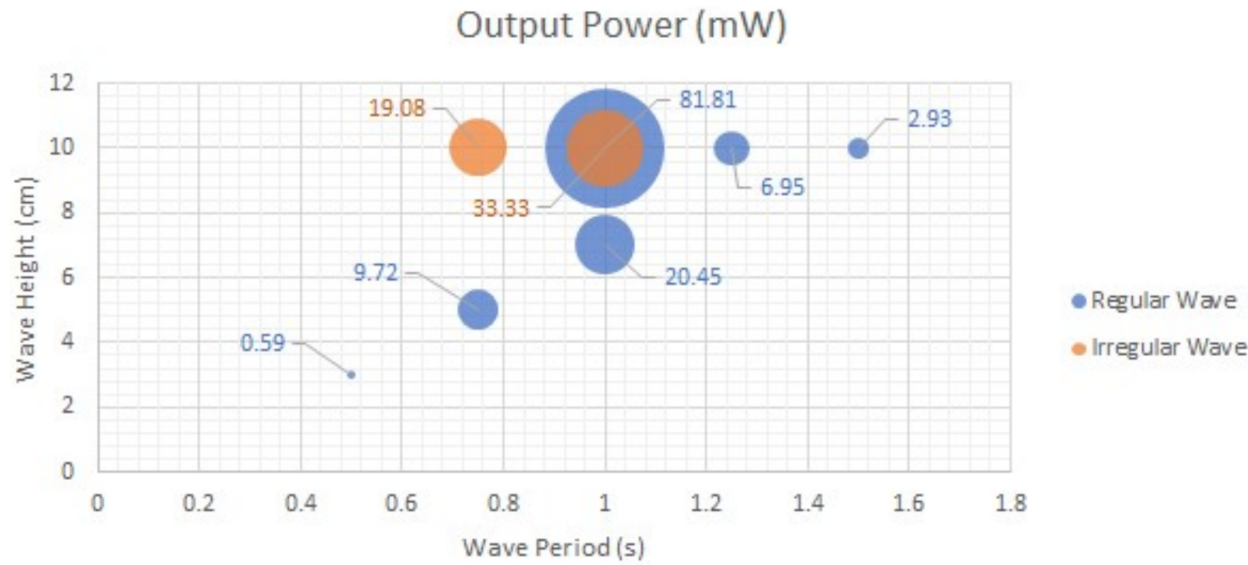

(a)
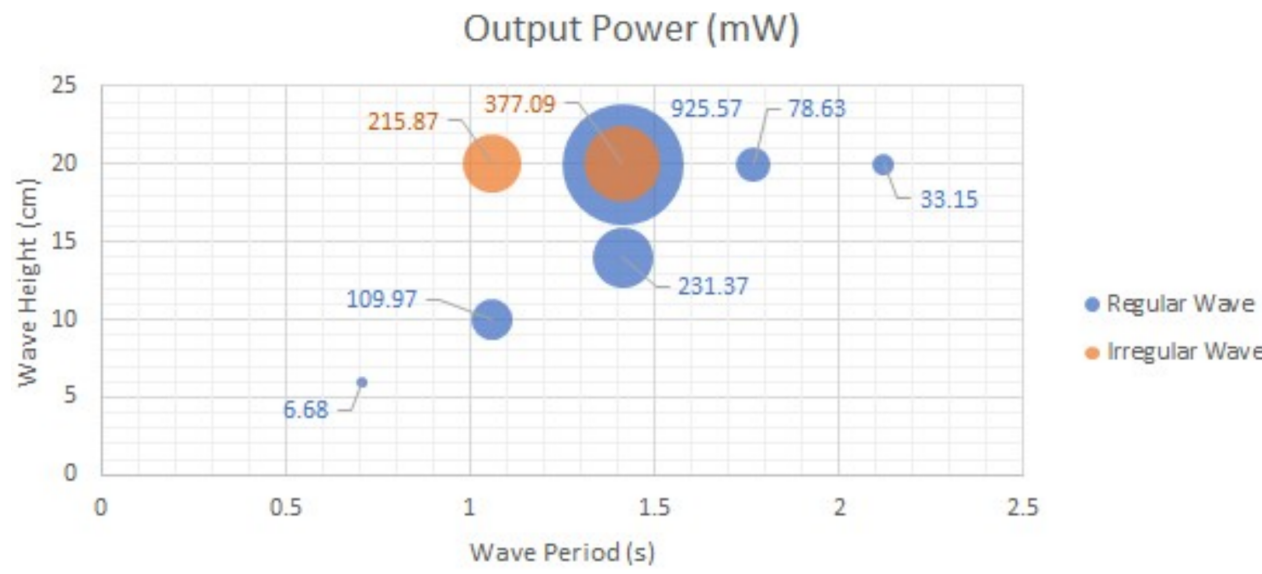

- Irregular Wave

(b)

Figure 11. (a) Power output calculated for the scaled model, (b) power output for the full-scale system.

When testing under regular wave conditions, the maximum power was calculated to be 81.81 milliwatts. This value was reached during wave testing with the following parameters: $1 \mathrm{~s}$ time period and $10 \mathrm{~cm}$ wave height. The scaled value for power and the corresponding wave characteristics was 925.63 milliwatts of power for waves with a $1.41 \mathrm{~s}$ wave period and a $20 \mathrm{~cm}$ wave height. Further, the peak-to-peak voltage measured for the device for this wave set was 12.7 volts. 


\section{Discussion}

Analyzing the results of the numerical models provides a general understanding of the power capacity for the developed energy harvester under two operating conditions. The locations selected for these studies were based on the availability and power density of ocean waves. Both Hawaii and California have strong waves with high ocean power density [32]. The required power for ocean observation purposes can vary from less than 0.5 watts to greater than 1000 watts, depending on the device and its sensors [6]. A simple profiling float may only require 100 milliwatts, while an autonomous underwater vehicle may use more than 150 watts of power.

An example of an observational system is the Self-Contained Ocean Observing Payload (SCOOP), developed by the National Data Buoy Center (NDBC) [36]. As the focus in this study is on buoys equipped with measurement systems and cameras to record wind speed, wind direction, barometric pressure, air temperature, humidity, and live video, the objective was to generate watt-level power to support these systems using one energy harvesting unit. The numerical analysis performed in this work considered a $2.1 \mathrm{~m}$ SCOOP [37] as the hub for the energy harvester. The results demonstrate that the energy harvester can generate more than 3 watts on average if it is installed on this buoy. Power can also be increased by installing multiple energy harvesters on each buoy, as demonstrated in Figure 12, or fine-tuning the harvester based on the wave characteristics in the selected location. It is important to note that the installation of these wave energy harvesting units on a new or currently operating buoy creates the need for re-calibration of the sensors to ensure that they are providing accurate measurements.

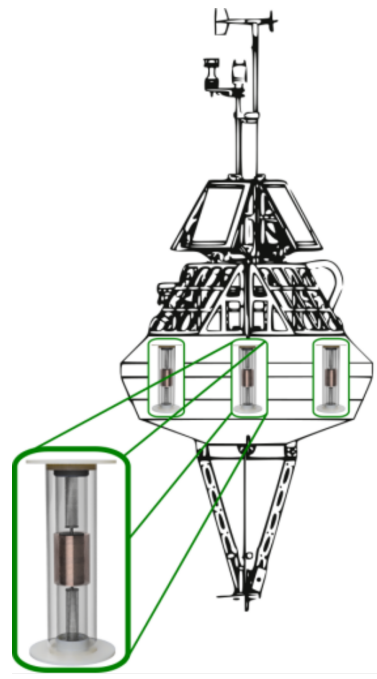

Figure 12. Schematic of installation of multiple energy harvesting units on one buoy.

The experimental testing in this work was primarily focused on the proof-of-concept for the proposed system. The results from these experimental tests generated an average power output value of around 0.9 watts. However, this value was obtained when the prototype was operating in a condition with a wave height value of $0.2 \mathrm{~m}$ and a wave period of $1.5 \mathrm{~s}$. In numerical simulations, the average wave height and wave period were around $1.5 \mathrm{~m}$ and $8-10 \mathrm{~s}$, respectively. The maximum power extraction was observed around the $1 \mathrm{~s}$ time period. Since the governing equation of the system is the Duffing equation, this peak power exemplifies nonlinear resonance, which is a shifted value from the linear resonance of the system [24]. The rotor's mass with two power magnets, three pole pieces, the rod, and the two focusing magnets is estimated at $1.6 \mathrm{~kg}$. The prototype's linear stiffness was set to $40 \mathrm{~N} / \mathrm{m}$ (using a single spring with limited motion of the rotor). Therefore, the linear natural frequency of the system is $0.8 \mathrm{~s}$. Despite initial observations, the system did not have low efficiency (as compared to the experimental results) when inputs from wave tank testing were considered as part of the analysis. A more rigorous method of 
comparing the performance is to estimate the efficiency of the system for each case and compare these results. Comparing the available wave energy (which can be estimated using the wave energy flux for the given wave properties) between the experimental tests and the numerical simulations, it is estimated that the available energy at the San Francisco location is about 400 times greater than the wave energy available during wave tank testing. Therefore, the large discrepancy between power output values obtained from experimental measurements and numerical modeling was already expected. Further, we did not optimize the system for those specific locations (Kapaau and San Francisco). Therefore, it is not surprising that the harvester had lower efficiency in numerical studies as compared to experimental studies.

Despite the progress made by this work, there are several limitations to the methodology used in the culmination of this research. First, the OceanEngineering library in OpenModelica, used for numerical modeling, requires that input coefficients be calculated using a frequency-domain potential flow Boundary Element Method (BEM) solver, such as WAMIT [38], AQWA [39], or NEMOH [40]. In this case, the input coefficients were obtained from the previous literature in this domain. However, in the case that the dimensions of the buoy structure changes, these hydrodynamic coefficients must be recalculated using the BEM solver. The second limitation to the research methodology pertains to the mechanical to electrical energy conversion modeling, which was performed in OpenModelica under the assumption that there was no loss in the system. In terms of experimental testing, the measurements were taken using only one wave gauge, providing the readings for water elevation during these tests. However, to accurately capture the effects of reflected waves, a minimum set of two wave gauges is required. In this work, the running time for the experiments was kept at short intervals, and a gradually sloped beach was used to minimize the impact of reflected waves on the results.

\section{Conclusions}

In this study, we introduced a relatively compact wave energy harvester, capable of producing watt-level power. This modular unit can be installed on both navigational and observational buoys to provide sufficient power for multiple sensors and/or communication systems. Based on the analysis for two locations, San Francisco in California and Kapaau in Hawaii, the numerical analysis demonstrated that each unit is capable of producing more than 3 watts of power on average. A proof-of-concept was built and tested in the wave tank to investigate the system's performance and its power generation. Experimental testing of a proof-of-concept revealed an average power extraction of up to 81 milliwatts for waves with a wave period of $1 \mathrm{~s}$, a wave height of $10 \mathrm{~cm}$, and a water depth of $91 \mathrm{~cm}$.

Considering the needs and power requirements for ocean observation, this energy harvesting device can be installed on various types of observational buoys to provide a longer lifespan for the system and a more reliable ocean observation unit.

Author Contributions: Conceptualization, J.F., J.S., A.S., L.D. and M.M.; methodology, N.V., J.S. and M.M.; software, N.V., J.F., A.S. and M.M.; validation, A.S., N.V. and M.M.; formal analysis, N.V., A.S. and M.M.; data curation, J.S. and M.M.; writing-original draft preparation, N.V., J.F., J.S., A.S., L.D. and M.M.; writing — review and editing, M.M.; visualization, J.F., A.S. and M.M. All authors have read and agreed to the published version of the manuscript.

Funding: This research was partially funded by the U.S. Department of Energy through the 2021 Marine Energy Collegiate Competition.

Data Availability Statement: Please contact the corresponding author for any additional data or model used in this paper.

Conflicts of Interest: The authors declare no conflict of interest. 


\section{References}

1. Glenn, S.M.; Dickey, T.D.; Parker, B.; Boicourt, W. Long-term real-time coastal ocean observation networks. Oceanography 2000, 13, 24-34. [CrossRef]

2. Dickey, T.D. Emerging ocean observations for interdisciplinary data assimilation systems. J. Mar. Syst. 2003, 40, 5-48. [CrossRef]

3. Favali, P.; Beranzoli, L. Seafloor observatory science: A review. Ann. Geophys. 2006 , 49, 515-567. [CrossRef]

4. Gould, J.; Sloyan, B.; Visbeck, M. In situ ocean observations: A brief history, present status, and future directions. Int. Geophys. 2013, 103, 59-81.

5. Zhao, T.; Xu, M.; Xiao, X.; Ma, Y.; Li, Z.; Wang, Z.L. Recent progress in blue energy harvesting for powering distributed sensors in ocean. Nano Energy 2021, 88, 106199. [CrossRef]

6. Green, R.; Copping, A.; Cavagnaro, R.J.; Rose, D.; Overhus, D.; Jenne, D. Enabling power at sea: Opportunities for expanded ocean observations through marine renewable energy integration. In Proceedings of the OCEANS 2019 MTS/IEEE SEATTLE, Seattle, WA, USA, 27-31 October 2019.

7. Hakkarinen, W. Solar power on the NOMAD buoy. In Proceedings of the 1970 IEEE International Conference on Engineering in the Ocean Environment-Digest of Technical Papers, Panama City, FL, USA, 1 September 1970; pp. $240-245$.

8. Chen, J.; Li, Y.; Zhang, X.; Ma, Y. Simulation and Design of Solar Power System for Ocean Buoy. J. Phys. Conf. Ser. 2018, 1061, 012018. [CrossRef]

9. Guerriero, P.; Attanasio, C.; Matacena, I.; Daliento, S. Merged Photovoltaic/Wave System for the Power Supply of a Marine Buoy for Harbour Monitoring. In Proceedings of the 2019 International Conference on Clean Electrical Power (ICCEP), Otranto, Italy, 2-4 July 2019; pp. 664-668.

10. Mayville, P.; Patil, N.V.; Pearce, J.M. Distributed manufacturing of after market flexible floating photovoltaic modules. Sustain. Energy Technol. Assess. 2020, 42, 100830. [CrossRef]

11. Omar, A.H.; Kadir, H.A.; Arshad, M.R. An Analysis of Energy Harvesting System for Ocean Data Acquisition System (ODAS) Buoy. In Proceedings of the 12th National Technical Seminar on Unmanned System Technology 2020; Springer: Singapore, 2022; pp. 161-170.

12. Cavagnaro, R.J.; Copping, A.E.; Green, R.; Greene, D.; Jenne, S.; Rose, D.; Overhus, D. Powering the blue economy: Progress exploring marine renewable energy integration with ocean observations. Mar. Technol. Soc. J. 2020, 54, 114-125. [CrossRef]

13. Hegarty, A.; Westbrook, G.; Glynn, D.; Murray, D.; Omerdic, E.; Toal, D. A low-cost remote solar energy monitoring system for a buoyed IoT ocean observation platform. In Proceedings of the 2019 IEEE 5th World Forum on Internet of Things (WF-IoT), Limerick, Ireland, 15-18 April 2019; pp. 386-391.

14. Becker, W.W. An Inquiry into the Feasibility of Using Ocean Surface Wave Energy to Power an Oceanographic Data Collection Buoy; Technical Report; Rhode Island Univ Kingston Dept of Ocean Engineering: Narragansett, RI, USA, 1969.

15. Isaacs, J.D.; Castel, D.; Wick, G.L. Utilization of the energy in ocean waves. Ocean Eng. 1976, 3, 175-187. [CrossRef]

16. Bastien, S.P.; Sepe, R.B.; Grilli, A.R.; Grilli, S.T.; Spaulding, M.L. Ocean wave energy harvesting buoy for sensors. In Proceedings of the 2009 IEEE Energy Conversion Congress and Exposition, San Jose, CA, USA, 20-24 September 2009; pp. 3718-3725.

17. Davis, E.P.; Ertekin, R.C.; Riggs, H.R. A buoy-based WEC device to provide low power to sensors. Int. Conf. Offshore Mech. Arct. Eng. 2009, 43444, 1109-1118.

18. Symonds, D.; Davis, E.; Ertekin, R.C. Low-power autonomous wave energy capture device for remote sensing and communications applications. In Proceedings of the 2010 IEEE Energy Conversion Congress and Exposition, Atlanta, GA, USA , 12-16 September 2010; pp. 2392-2396.

19. Gemme, D.A.; Greene, H.R.; Tucker, T.A.; Sepe, R.B.; Bastien, S.P. Hybrid resonant wave energy harvesting buoy for sensor applications. In Proceedings of the 2013 OCEANS, San Diego, CA, USA, 23-27 September 2013; pp. 1-6.

20. Grilli, S.T.; Grilli, A.R.; Spaulding, M.L.; Bastien, S.P.; Sepe, R.P. Small buoys for energy harvesting: Experimental and numerical modeling studies. In Proceedings of the Twenty-First International Offshore and Polar Engineering Conference, Maui, HI, USA, 19-24 June 2011.

21. Harne, R.; Schoemaker, M.; Dussault, B.; Wang, K. Wave heave energy conversion using modular multistability. Appl. Energy 2014, 130, 148-156. [CrossRef]

22. Wu, S.; Liu, Y.; An, Q. Hydrodynamic Analysis of a Marine Current Energy Converter for Profiling Floats. Energies 2018, 11, 2218. [CrossRef]

23. Mann, B.; Sims, N. Energy harvesting from the nonlinear oscillations of magnetic levitation. J. Sound Vib. 2009, 319, 515-530. [CrossRef]

24. Masoumi, M.; Wang, Y. Repulsive magnetic levitation-based ocean wave energy harvester with variable resonance: Modeling, simulation and experiment. J. Sound Vib. 2016, 381, 192-205. [CrossRef]

25. Chakrabarti, S.K. Hydrodynamics of Offshore Structures; WIT Press: Southampton, UK, 1987.

26. Viswanathan, S.; Holden, C. Towards the development of an ocean engineering library for openmodelica. Int. Conf. Offshore Mech. Arct. Eng. 2019, 58851, V07BT06A025.

27. Meeker, D. FEMM 3.4 Magnetostatic Tutorial. 2004. Available online: http://www.femm.info/Archives/doc/femm34tutor.pdf (accessed on 9 January 2022) . 
28. Fritzson, P.; Aronsson, P.; Pop, A.; Lundvall, H.; Nystrom, K.; Saldamli, L.; Broman, D.; Sandholm, A. OpenModelica-A free open-source environment for system modeling, simulation, and teaching. In Proceedings of the 2006 IEEE Conference on Computer Aided Control System Design, 2006 IEEE International Conference on Control Applications, 2006 IEEE International Symposium on Intelligent Control, Munich, Germany, 4-6 October 2006; pp. 1588-1595.

29. Van Rossum, G.; Drake, F.L. Python 3 Reference Manual; CreateSpace: Scotts Valley, CA, USA, 2009.

30. Bitter, R.; Mohiuddin, T.; Nawrocki, M. LabVIEW: Advanced Programming Techniques; CRC Press: Boca Raton, FL, USA, 2006.

31. Fritzson, P.; Engelson, V. Modelica-A unified object-oriented language for system modeling and simulation. In European Conference on Object-Oriented Programming; Springer: Berlin/Heidelberg, Germany, 1998; pp. 67-90.

32. Scott, G.N. National Wave Energy Resource Refinement Using 30-Year Hindcast; Technical Report; National Renewable Energy Lab. (NREL): Golden, CO, USA, 2018.

33. Jain, A.; Goupee, A.J.; Robertson, A.N.; Kimball, R.W.; Jonkman, J.M.; Swift, A.H. FAST code verification of scaling laws for DeepCwind floating wind system. In Proceedings of the Twenty-Second International Offshore and Polar Engineering Conference, Rhodes, Greece, 17-22 June 2012.

34. Wheeler, H.A. Inductance formulas for circular and square coils. Proc. IEEE 1982, 70, 1449-1450. [CrossRef]

35. Bouchard, R.H.; Jensen, R.E.; Riley, R.; LeBlanc, L.A.; Fiorentino, L.A. Calibration and Field Evaluation of the National Data Buoy Center's New Wave Measurement System. In Proceedings of the 98th American Meteorological Society Annual Meeting, Austin, TX, USA, 7-11 January 2018.

36. Kohler, P.C.; LeBlanc, L.; Elliott, J. SCOOP-NDBC's new ocean observing system. In Proceedings of the OCEANS 2015MTS/IEEE Washington, Washington, DC, USA, 19-22 October 2015; pp. 1-5.

37. Hall, C.; Bouchard, R.H.; Riley, R.; Stewart, R.; Wang, D.; DiNapoli, S. Emerging National Data Buoy Center (NDBC) Wave Systems. In Proceedings of the Conference: JCOMM DBCP-34 Meeting, Cape Town, South Africa, 23-26 October 2018.

38. Lee, C.H.; Newman, J.N. Wamit User Manual; WAMIT, Inc.: Chestnut Hill, MA, USA, 2006; p. 42.

39. Ansys, A. AQWA User'S Manual Release 17.0; ANSYS Inc.: Canonsburg, PA, USA, 2016.

40. Babarit, A.; Delhommeau, G. Theoretical and numerical aspects of the open source BEM solver NEMOH. In Proceedings of the 11th European wave and tidal energy conference (EWTEC2015), Nantes, France, 6-11 September 2015. 